\title{
"Reading" ability of students in Nepal
}

\author{
Kumar Narayan Shrestha
}

\begin{abstract}
Reading is the main means of exposure for English as a second or foreign language learner. The present study aimed at finding out the reading comprehension ability (RCA) of the master level students, majoring in English at Tribhuvan University (TU), Nepal in relation to IELTS academic reading test. Administering a sample testand analyzing its data, it was found that the RCA of the master level students is not adequate in terms of IELTS standard since their RCA is $41 \%$ and the IELTS score is 3.70 band. This shows that they are at 'Extremely Limited User' level for the admission policies in IELTS recognised countries and not eligible to get the admission in the IELTS recognised Universities. The implication of the study is that there is a need for reading skills development programme incorporating the enhancement of inferential, predictive and interpretive skills.
\end{abstract}

Key words: Reading Comprehension, Reading Skills, IELTS, IELTS Academic Reading

\section{Introduction}

Reading is one of the basic skills of language. Among listening, speaking, reading and writing; reading is the third but a vital skill required for developing language. It is an active receptive skill. Reading is to grasp information from graphic representation of language (Lado, 1962). It is the most common and the easiest means of receiving printed information. Similarly, it is the sole means of frequent exposure to language for the second or foreign language learners. It is the combination of both the visual and mental experience. The visual process is to look at the text in the meantime the mind decodes it for comprehension. The mental process needs interaction of the visual input with the prior knowledge of the reader for comprehension.
In any text, information is presented in the written from, but the way of obtaining the information may require different skills and sub-skills of reading. Harmer (2008) points out that the readers should acquire some reading skills: scanning, skimming, reading for pleasure and reading for detailed comprehension. Using these skills, a good reader can obtain the required information. The information may refer to our intellectual, factual, emotional contents and so on.

Sadoski (2004 as cited in Althiemoolam \& Kibui) claims that comprehension is pivotal to reading as it occupies the central place on the continuum where input from the print and the reader is in central balance. Reading comprehension is a process of obtaining the required information from a written text as efficiently as possible. That 
is to say, it is thorough understanding of a message in a text. Comprehension does not simply mean to decode the words in the text. Even after the individual words have been identified, the other skills are also necessary to perceive the underlying meanings. The meaning of an individual sentence, paragraphs and sometimes other higher unit(s) of the text should be assimilated to obtain the main idea of the text. Therefore, the reader has to actively strive and work to get the meaning out. As Nuttall (1996) mentions that a good and competent reader grasps the significant value of the written text. Similarly, Goodman (1976) and Smith (1978) (as cited in Awasthi et al.,) have pointed out that information is richly available on the printed page, and there are a number of ways of determining the identity of a letter or a word. The ways of determining meanings from the texts need reading skills and the skills of the readers may have to stretch from the lower level to the higher levels of language for better comprehension. This involves understanding the writer's presuppositions sufficiently to recognise what he means by a particular statement, not just what he says, but why he says it. That is to say, the lack of understanding of the common intentions between the reader and the writer may make the reader's comprehension incomplete.

Similarly, for Chall and Stahl (2009), reading comprehension comprises a series of sub-skills, such as understanding word meanings in context, finding the main idea, making inferences about information implied but not stated, and distinguishing between fact and opinion. It means reading comprehension includes many sub-skills such as deriving meaning in context, getting gist, making underlying inferences and recognizing fact and opinion. Hui-lung Chia (2001) believes that reading comprehension is an interaction between a reader's prior knowledge and the information encoded in the text. Basically, reading comprehension needs the mastery of two interrelated skills. Firstly, to perceive the specific relationships between the written symbols and its meaning and secondly, understanding the meaningful representation of the basic grammatical structures in the given context. Similarly, reading comprehension is also necessary for the better learning of a language. As Nation (1997) concluded, "Success in reading ... makes learners come to enjoy language learning and to value their study of English" (p.16).

The learning and mastery of English language in Nepal poses more complex challenges because the classroom is the only environment where the learner can hear, learn and try to speak it. In the context of this study also, the participants have limited exposure and reinforcement outside the classroom. Therefore, reading is one of the prominent means of exposure to learn English. In this regard Gebhard (2000) points out that in English as a second language setting there are fewer opportunities for learners to apply what they study to communicative situation outside the classroom since the only comprehensible English some of these learners hear and read is in the classroom. Furthermore, in the modern society the learners are confronted with various material in their daily life that need to be read, analysed, interpreted and understood. More precisely, the craze for international degree in the youngsters has made English and standardised English language test vital. Therefore, reading comprehension is necessary for a purpose other than learning the language itself.

This study is on IELTS based reading comprehension ability of graduate students at TU. It deals only with academic reading of IELTS. The participants in the research 
project speak Nepali as their mother tongue. The acquisition of English, however, is quite different from Nepali as it is only learned in schools and colleges where it is taught as a subject. It means that the participants of the research hardly practise English after school/college because Nepali language is used in their homes and outsides.

\section{What is IELTS?}

The International English Language Testing System (IELTS) is designed to assess the language ability of candidates who need to study or work where English is used as the language of communication. IELTS test is independent of any curriculum or teaching method, the proficiency level of any test taker can be compared with that of any other students, regardless of academic background or English training. IELTS is probably the most often used examination in the admission process of foreign students to colleges and universities in British, Australian, Canadian, New Zealand and American education institutions. It is also recognised by professional bodies, immigration authorities and other government agencies.

IELTS is a proficiency test administered at the authorized centres throughout the world. It has two modules of the test: Academic Module and General Training Module. The Academic Module is meant for the candidates taking the test for entry to undergraduate or postgraduate studies or for professional reasons in the universities and colleges in the United Kingdom, Australia, New Zealand, Canada and the USA. And the General Training Module is meant for the candidates taking the test for entry to vocational or training programme in these countries. IELTS covers the four language skills, namely listening, speaking, reading and writing. It comprises 2.45 hours full length test.
The IELTS academic reading test is of 60 minutes. Listening, Reading and Writing are completed in one sitting. The Speaking test may be taken on the same day or up to seven days before or after the other tests. All test takers take the same Listening and Speaking tests, while the Reading and Writing tests differ depending on whether the test taker is taking the Academic or General Training versions of the test. IELTS is designed to assess the language ability of candidates needing to study or work in the countries where English is used as the first language both for communication and for medium of instruction. IELTS result consists of a score in each of the four skills (listening, speaking, reading, and writing) which is then averaged to give the Overall Band Score or final mark. The performance of candidate is rated in each skill on a scale of 9 to 1 band(s). The minimum score accepted for a course ranges from 5.0 to 7.5 depending upon course and depending upon courses and institutes. The most common requirement is a band score of 6.0 to 6.5. Mostly undergraduate programmes require minimum IELTS scores of 5.5 and graduate programmes require a minimum score of 6.5. IELTS scores are valid for maximum two years. The researcher has selected IELTS not other international test system because of its increasing popularity.

\section{Main Aspects of IELTS Academic Reading}

The topics in IELTS are of general interests but they are related to an academic subject. They often deal with global issues, such as the environment, language, conservation, tourism, etc.

Although the topics may seem unfamiliar to examinees, none of the passages contains technical information or specialist vocabulary that is not explained or cannot be understood by an educated reader. Sometimes, however, the examinee will 
need to ignore unknown words or guess their meaning.

IELTS tests a range of reading skills that a learner needs for study purposes. According to Jakeman and McDowell (2006, p. 31), these are following main skills that IELTS tests:

- $\quad$ reading quickly to get a general idea or finding a particular word

- $\quad$ finding detail or factual information

- $\quad$ understanding themes and main ideas

- $\quad$ identifying views, arguments and claims

- identifying the overall theme of the passage.

\section{The Study}

This study was a survey done among the students at TU. The subjects were the graduates in English and studying Master degree at TU. The data was collected from learners representing four colleges namely University Campus (UC) Kritipur, Mahendra Ratna Campus (MRC), Tahachal, Ratna Rajya Laxmi Campus (RRC), Exhibition Road and Patan Multiple Campus (PMC) Patandhoka of Kathmandu valley on the bases of three comprehension passages given as a sample test in ACTION PLAN for IELTS (see appendix I). The details of the study are briefly presented here:

\section{Objectives of the Study}

The objectives of the research were to find out English reading comprehension ability of the graduate students in IELTS test and to suggest some pedagogical implications.

\section{Methodology}

The study was entirely field based. It was conducted using quantitative research methodology. Mainly two types of sources of data were utilized; primary and secondary. The researcher visited the different four colleges of $\mathrm{TU}$. and administered the sample test paper to the students of M.A. and M. Ed. Among them, two were colleges of Humanities and Social Sciences and two were colleges of Education. The responses were interpreted and analysed using simple statistical tools. Similarly, different books related to IELTS, web sites, journals and articles, etc. were consulted to back up the obtained data.

\section{Population}

The population of this study consisted of eighty-eight master's level students of TU. They were from four different campuses as mentioned above. They were selected as the population of the study since the researcher was interested in knowing their reading comprehension level in comparison to IELTS academic reading test. So, the study area and the population were selected purposively. Then, the students were selected randomly from among the interested students.

\section{Research Instrument}

The tool used in the research was a test which was a sample test paper of IELTS taken from ACTION PLAN for IELTS. It consisted of three sections with forty questions. There were three texts, which are taken from journals, magazines and newspapers. The texts were the topics of general interests. At least one text contained detailed argument.

A variety of question types was used, including multiple choice items, identifying information (True/False/Not Given), 
identifying writer's views / claims (Yes/ No/Not Given), matching information, matching headings, matching features, matching sentence endings, sentence completion, summary completion, note completion, table completion, flow-chart completion, diagram label completion, short answer questions.

\section{Analysis and Interpretation}

The researcher analyzed the reading comprehension ability of students with reference to IELTS score and with reference to the evaluation scheme of TU. The evaluation scheme of TU categorizes the marks into four different categories. While analyzing the data, responses were assigned marks. At master level, TU has following marking scheme:

- Third division or pass division $40 \%$

- Second division 50\%

- First division $60 \%$

- Distinction $75 \%$

On the contrary, IELTS has different system of marking. It has certain criteria to assign the band score (see appendix-II). Its result consists of a score in each of the four language skills (listening, speaking, reading, and writing) which is then averaged to give the Overall Band Score or final mark. Performance is rated in each skill on the scale of 9 to 1 . According to Jakeman and McDowell (1996), the nine overall Bands and their statements are as follows:

- Expert user

- Very good user

- Good user

- Competent user

- Modest user

- Limited user
- Extremely limited user 3

- Intermittent user 2

- Non user 1

- Did not attempt the test 0

While analyzing the data, the responses were assigned allocated marks. For one correct response, one mark was given. The researcher determined the students' responses correct or incorrect on the basis of answer sheets provided by IELTS. The band score was provided following the IELTS band score table. The band score increases as the number of correct responses increase. Out of total 40 questions, one correct response equal to 2 , 4 to 9 correct responses equal to 3 , likewise the marking scheme goes on more or less in the same way till 9 band score (see appendix-2).

\section{The Total RCA of the students as a whole}

The total RCA of the students can be shown in the table as follow:

The total RCA of the students can be shown in the table as follow:

This table shows that out of 9 band score, the students of University Campus obtained 4.13 band, i.e., $45.89 \%$ and MahendraRatna Campus obtained 3.90 band, i.e., 43.39\%. This indicates that the RCA of the graduate students of the Faculty of Education of TU is not so satisfactory. Regarding IELTS policy for the admission, 4 band score is levelled as 'Limited User'. So, the students

\begin{tabular}{llll}
\hline S.N. & Campuses & $\begin{array}{l}\text { Band } \\
\text { score }\end{array}$ & $\begin{array}{l}\text { Percentage } \\
\text { score }\end{array}$ \\
\hline 1 & University Campus, Kritipur & 4.13 & 45.89 \\
2 & Mahendra Ratna Campus & 3.90 & $43.39 \%$ \\
3 & Ratna Rajya Laxmi Campus & 2.86 & 31.72 \\
4 & Patan Multiple Campus & 3.90 & 43.33 \\
5 & Total (RCA) & 3.70 & 41.01 \\
\hline
\end{tabular}

Table 1: Total RCA of students 
of Faculty of Education do not meet the required level of reading proficiency in IELTS for entry to academic programmes in IELTS recognised countries.

Similarly, their score is third division/pass division in terms of evaluation system of TU since their percentage is $44.64 \%$ in average. So, we can conclude that the proficiency of the students of Faculty of Education of TU is below the expected level of proficiency.

Likewise, out of 9 band score, the students of RatnaRajyaLaxmi Campus obtained 2.86 band and the students of Patan Multiple Campus obtained 3.90 band. This data shows that the students of Patan Multiple Campus have higher RCA than those of Ratna Rajya Laxmi Campus. According to IELTS system, Ratna Rajya Laxmi Campus is levelled as 'Intermittent User' due to their 2.86 band likewise Patan Multiple Campus is levelled as 'Extremely Limited User' due to their 3.90 band. In total, their average score is below the pass division if we analyze from the point of view of the evaluation system of TU.

The table above also shows the overall RCA of the graduate students of TU. on the basis of IELTS. The students obtained the overall band score of 3.70 , i.e. $4.01 \%$ as a whole in IELTS. This means that the overall RCA of the graduate students of TU in the English language is not adequate. The research further shows that the average RCA of the students of the Faculty of Education is $7.05 \%$ more than that of Faculty of Humanities on the basis of IELTS.

However, there is not fixed pass mark in IELTS; the institution where the students want enrolment decides whether the score is appropriate for the demands of the course of study or training they want to undertake. As a general result, scores below band 5 in any one skill are considered to be too low for academic study; scores above band 6 are deemed to be adequate to good. Overall band scores of 5 or 6 are borderlines and may not be acceptable at many Universities. In this study, out of 9 band as full band, students securing more than 6 band scores were not found.

Out of the total population of the study i.e. 88 , only 16 candidates i.e. $18.18 \%$ obtained the score between 5 and 6 band scores. Most undergraduate programmes require minimum IELTS score of 5.5 band and graduate programmes requires a minimum IELTS score of 6.5 band. This shows that only $5.68 \%$ students scoring 6 band are acceptable for undergraduate programmes. But some of the institutes also accept 5 to 6 band score for graduate and post-graduate programmes.

On the other hand, 72 students out of 88 obtained the scores ranging from 1 to 4 band scores. These students' academic level is relatively quite unsatisfactory than those of the earlier group on the basis of IELTS. Even though, some of them deserve pass division marks on the basis of TU evaluation system.

Table 2: Text-wise Analysis of the Proficiency

\begin{tabular}{lllcr}
\hline S.N Reading Passages & \multicolumn{3}{l}{$\begin{array}{l}\text { Average Percentage Remark } \\
\text { Score }\end{array}$} \\
\hline 1. & Reading Passage 1 & 6.11 & $47 \%$ & Highest \\
2. & Reading Passage 2 & 3.19 & $24.54 \%$ & \\
3. & Reading Passage 3 & 1.35 & $9.64 \%$ & Lowest \\
\hline
\end{tabular}

The order of the passages are of increasing difficulty on the topics of general interest and related to academic subjects such as the environment, language, conservation, 
tourism, etc. It is the general convention of the IELTS.

The table 2 shows that RAC of the students on the basis of the type of text. The different texts contain different subject matter (theme) i.e. the Reading Passage- 1 , is related with 'Egyptian Civilization', the Reading Passage-2 is related with 'insects having sticking power' and the Reading Passage- 3 is related with 'the attributes of natural and social sciences'. The students have obtained different scores in different texts. They have performed the highest score in the Reading Passage- 1 i.e. 47\%. Their RCA in Reading Passage-2 and Reading Passage- 3 is not satisfactory since their scores are $24.54 \%$ and $9.64 \%$ respectively. It shows that the students have performed better in the easy passage than that of difficult ones. To be more specific, since the activities of the Reading Passage- 2 and the Reading Passage- 3 need thorough understanding of the text, their performance is comparatively low. Therefore, it can be said that the students lack inferential, interpretive and analytical skills.

Table 3: Item-wise Analysis of the Proficiency

\begin{tabular}{|l|l|l|l|l|}
\hline S.N. & Test Items & $\begin{array}{l}\text { Average } \\
\text { Score }\end{array}$ & Percentage & Remarks \\
\hline 1. & Sentence Completion & 1.18 & 39.33 & \\
2. & Labelling a Diagram & 2.49 & 62.25 & Highest \\
3. & True/False/ Not Given & 2 & 40 & \\
4. & Multiple Choice & 0.44 & 44 & \\
5. & Pick from a List & 1.64 & 32.8 & \\
6. & Finding Information & & & \\
& in Paragraphs & 0.47 & 11.75 & \\
7. & Sentence Completion & & & \\
8. & with a Box & 1.08 & 27 & \\
9. & Paragraph Headings & 0.32 & 5.33 & \\
10. & Summary Completion & 0.19 & 4.75 & Lowest \\
\hline
\end{tabular}

The table 3 shows the item-wise performance of eighty eight students in Sentence Completion, Labelling, True/ False/Not Given, Multiple Choice, Pick from a list, Finding Information in Paragraphs, Sentence Completion with a Box, Paragraph Headings, Summary Completion and Classification. As the table shows, the students showed the very good performance in Labelling a Diagram i.e. $62 \%$. On the other hand, the students showed only satisfactory performance in True/False/Not Given and Multiple Choice items. It means they obtained $40 \%$ and $44 \%$ in these items respectively. But in Sentence Completion, Pick from a list, Finding Information in Paragraphs, Sentence Completion with a Box, Paragraph Headings, Summary Completion and Classification, they deserved, $39.33 \%$, $32.8 \%, 11.75 \%, 27 \%, 5.33 \%, 4.75 \%$ and $21.25 \%$ respectively which are satisfactory. It gives the impression that students are more proficient in Labelling a Diagram i.e. $62.75 \%$ and least proficient in Summary Completion i.e. $4.75 \%$. In other words, the respondents are more proficient in factual reading than in inferential reading. It shows that a number of learners were unable to identify context clues in the reading texts.

\section{Findings}

This research has shown that the graduate students of TU specializing in English do not have adequate RCA, since their average RCA is $41.11 \%$ and the IELTS score is 3.70 band. This has shown that they are at 'Extremely Limited User' level as per the admission policies in IELTS recognised countries and do not get the admission in their universities. Only 16 students i.e. $18.18 \%$ obtained the scores between 5 to 6 band. It shows that only $18.18 \%$ students have ability to get admission in the colleges in IELTS recognised countries. These findings further show that the RCA of 
Nepalese graduate students is lower than that of IELTS recognised countries. The research shows that the average RCA of the students of the Faculty of Education is $7.05 \%$ more than that of Faculty of Humanities on the basis of IELTS. On the basis of texts, the RCA of the students of both the faculties is $47 \%$ in Reading Passage1, 24.54\% in Reading Passage-2 and 9.64\% in Reading Passage- 3 . There is significant difference $(57.5 \%)$ between the most difficult items i.e. Summary Completion and the easiest item i.e. Labelling a Diagram.

\section{Discussion of findings}

The study revealed that the graduate students at TU do not have wide knowledge of world and the English. Since the texts were not literary in nature they failed to perform well. More specifically the students from arts faculty deserved $(37.52 \%)$ lower score than students from education faculty $(44.64 \%)$. It showed that their course does not include varieties of content areas and they do not have proper skills of reading. Similarly, the students had the best performance in 'Labelling a Diagram' which could be directly picked out from the text. On the other hand, their performance is the poorest in 'Summary Completion' which needs thorough understanding of the text. This showed that they know the dictionary meaning of the words but fail to understand the message. In other words, they are good at factual reading and skimming but not in inferential reading. In reading comprehension, only dictionary meaning of the words is not adequate. In this regard Schckle (2009) in Ferreira (2009) says that for learners to read successfully they need a combination of decoding and understanding where they are able to use their knowledge of letters and words to make sense of when they read. It means the readers should be able to infer or deduce the underlying meaning of the text for comprehension.

Similarly, Compton (2005) in his study on word recognition, transfer, and reading acquisition found that skilled comprehension readers are rapid at word decoding than less skilled readers. He also found that the establishment of decoding skills through structured intervention acted as a boot strapping mechanism to improve reading skills, such as word recognition skill, reading fluency, and comprehension (as cited in Althiemoolam\&Kibui, 2012, p.11). From this it is evident that skilled readers use their reading skills for connotative reading rather than denotative one. Therefore, reading comprehension is not a mechanical activity. It needs various skills of reading and other sub-skills. According to Althiemoolam and Kibui (2012),"Reading for meaning depends upon vocabulary knowledge, syntactic integration, inferences, and other higher order overlapping skills that make demands on the same mechanism responsible for converting and the printed code into the language code" (p.11). This suggested that reading comprehension depends on the knowledge of vocabulary, syntactic integration, inference and other higher skills.

Likewise, in a study on the role of comprehension of meaningful language input in young adults' second language learning by Paribakht, and Wesche (1992) indicated superior gains in the comprehension-based class in text comprehension and discourse processing, despite smaller gains in grammatical knowledge. It shows links between comprehension of meaning and acquisition of vocabulary. That is to say explicit grammar instruction is not needed to enhance comprehension skills, but vocabulary knowledge is necessary.

$48 \quad$ Journal of NELTA, Vol 20 No. 1-2, $\quad$ December 2015 
The most of the studies aforementioned highlighted the significant role of vocabulary as a means to analyse the text. In addition to this, vocabulary also provides the context clues to the reader to derive the meaning of the author. Instead of vocabulary, the readers also need the knowledge of morphology, syntax and discourse as a whole. Furthermore, the knowledge of genres, content areas and style of writing are equally crucial to infer the meaning of any text.

\section{Implications of the findings}

The study shows that the learners need the exposure to adequate vocabularies through varieties of text, genres, and contents areas. While teaching language, they should be made familiar with all the skills that are required for effective reading comprehension including inferential, predictive and interpretive skills. Furthermore, poor proficiency can be addressed through appropriate curriculum and modern approaches of teaching.

\section{Conclusion}

The study has shown that the graduate students at TU are experiencing difficulty in reading comprehension. Some reading difficulties experienced by the learners within the context of this study could include lack of background knowledge, reading skills, the style and complexity of the language, inadequate experience and exposure to the varieties of texts. One of the causative agents behind these difficulties is poor and traditional teaching method. Therefore, the teachers should use modern teaching methods that would improve their learners' reading skills. The teachers should enhance their learners' interpretive, critical, predictive and analytical skills through their teaching.
Similarly, the learners should be exposed to varieties of authentic texts. As Guariento and Morley (2001) believe that using authentic text is an important way to maintain and increase learners' motivation in language learning. That means the authentic texts motivate the learners and help them acquire the foreign language naturally. Along with authentic texts, simplified texts also help learners accelerate the process of language learning. As McGregor (1989) found that, whenever learners face difficulty in comprehending a reading text, their problem can be remedied if the text is presented to them after simplifying it by using the highfrequency words, as learners understand the more frequent ones (Wang \&Koda, 2005, p. 89

Finally, as Nuttall (1996) observed, "Reading is caught, not taught" (p.229). The students should be self motivated for reading. They should be aware that reading is not an overnight activity. A sustained reading effort makes a good reader in a long run.

\section{References}

Athiemoolam, L., \& Kibui, A. (2012). An analysis of Kenyan learners' proficiency in English based on reading comprehension and vocabulary. Journal of NELTA, 17, (12), 1-13.

Awasthi, et al. (Eds.). (2009). New Generation English. Kathmandu: Vidhyarthi Prakashan.

Chall, J.S., \& Stahl, S. (2008). Reading. Microsoft@ encarta® 2009 [DVD]. Redmond, WA: Microsoft Corporation.

Chia, H.(2001). Reading activities for effective top-down processing. English Teaching Forum, 39 (1), 22. 
Gebhard, J.G. (2000). Teaching English as a foreign or second language: A teacher self-development and methodology guide. Michigan, U.S.A.: The University of Michigan Press.

Guariento, W., \& Morley, J. (2001). Text and task authenticity in the EFL classroom. ELT Journal 55, (4), 347-353.

Harmer, J. (2008). How to teach English. London: Longman

Jakeman, V., \& McDowell, C. (1996). Cambridge practice tests for IELTS 1. Cambridge: Cambridge University Press.

Jakeman, V., \& McDowell, C. (2006). Action lan for IELTS. Cambridge: Cambridge University Press.

Lado, R. (1962). Language teaching. London: Longman.

Nation, P. (1997). The language learning benefits of extensive reading. The Language Teacher, 21(5), 13-16

Nuttall, C. (1996). Teaching reading skills in a foreign language (2nd ed.). Oxford: Heinemann.

Paribakhat, T. S., \&Wesche, M. B. (1992). A methodology for studying the relationship between comprehension and second language development in a comprehension-based/ESLProgram. Retrieved on January 25, 2012 from http://web28.epnet.com

Sadoski, M. (2004). Conceptual foundations of teaching reading. New York: The Guilford Press.

Schckle, E. (2009). Strategies and practices for effective reading. In A Ferriera (Ed.), Teaching language (pp.133-146). Gauteng: Macmillan.

Wang, M. \& Koda, K. (2005). Commonalities and differences in word identification skills among learners of English as a second language. Language Learning, 55 (1), 7178.

\section{Author's bio}

Kumar Narayan Shrestha, M.Ed. and M.A., is an English faculty at Tribhuvan University, Nepal. He has been associated with the field of teaching for sixteen years. He has taught to nursery to tertiary level students. His professional interests include ELT, translation and literature. To his credit, there are some co-edited books and translations.

\section{Appendix-1}

IELTS Band Score Tables for Reading

\begin{tabular}{|l|l|l|}
\hline S.N. & $\begin{array}{l}\text { Scores Band } \\
\text { (Correct Responses) }\end{array}$ & Scores \\
\hline 1. & 1 & 1 \\
\hline 2. & 2 to 3 & 2 \\
\hline 3. & 4 to 9 & 3 \\
\hline 4. & 10 to 15 & 4 \\
\hline 5. & 16 to 22 & 5 \\
\hline 6. & 23 to 28 & 6 \\
\hline 7. & 29 to 35 & 7 \\
\hline 8. & 36 to 39 & 8 \\
\hline 9. & 40 & 9 \\
\hline
\end{tabular}

